\title{
Blockchain-based applications in shipping and port management: a literature review towards defining key conceptual frameworks
}

Sergey Tsiulin and Kristian Hegner Reinau

Department of the Built Environment, Aalborg Universitet, Aalbog, Denmark

Olli-Pekka Hilmola
Nikolay Goryaev

Department of Exploitation of Auto Transport, South Ural State University, Celabinsk, Russian Federation, and

Ahmed Karam

Department of the Built Environment, Aalborg Universitet, Aalbog, Denmark and Department of Mechanical Engineering (Shoubra), Benha University, Egypt

\begin{abstract}
Purpose - The purpose of this paper is to examine and to categorize the tendencies of blockchain-based applications in the shipping industry and supply chain as well as the interrelations between them, including possible correlation of found categories with theoretical background and existing concepts. This study also explores whether blockchain can be adopted into existing maritime shipping and port document workflow management.

Design/methodology/approach - The current study builds a conceptual framework through a systematic project review carried along with scientific and grey literature, published in journals and conference proceedings during the past decade and giving information or proposals on an issue.

Findings - The results showed that reviewed projects can be compiled into three main conceptual areas: document workflow management, financial processes and device connectivity. However, having clear interlinkages, none of the reviewed projects consider all three areas at once. Concepts associated with maritime document workflow received broad support among the reviewed projects. In addition, reviewed projects unintentionally follow the similar goals that were laid down within port management scientific projects before the introduction of blockchain technology.

Originality/value - This study contributes to research by revealing a consistent framework for understanding the blockchain applications within maritime port environment, a less-studied part of

(c) Sergey Tsiulin, Kristian Hegner Reinau, Olli-Pekka Hilmola, Nikolay Goryaev and Ahmed Karam. Published by Emerald Publishing Limited. This article is published under the Creative Commons Attribution (CC BY 4.0) licence. Anyone may reproduce, distribute, translate and create derivative works of this article (for both commercial and non-commercial purposes), subject to full attribution to the original publication and authors. The full terms of this licence may be seen at http:// creativecommons.org/licences/by/4.0/legalcode

This research was supported as part of BLING - Blockchain In Government, an Interreg project supported by the North Sea Program of the European Regional Development Fund of the European Union.

This paper forms part of a special section "Blockchain and the Multinational Enterprise", guest edited by Rui Torres de Oliveira, Marta Indulska and Tatiana Zalan.
\end{abstract}

Blockchainbased applications

Received 30 April 2019 Revised 1 October 2019 3 March 2020 Accepted 10 April 2020 
RIBS

30,2

202

blockchain implementation in the supply chain field. Moreover, this work is the first to find out conceptual intersections and correlations between existing projects, mapping current tendencies and potentially increasing knowledge about the field.

Keywords Shipping, Supply chain, Conceptual framework, Blockchain, Maritime port management, Port community system, Internet of things

Paper type Literature review

\section{Introduction}

In recent years, mass digitalization, rapid development and advanced usage of the Internet have been among the greatest drivers of business development and coordination, process optimization and cost reduction. The majority of transport freight hubs, consolidation centers, terminals and ports face a multitude of business challenges (Nordtømme et al., 2015; Lindholm, 2010). Cost management approaches remain not fully optimized and periodically inefficient, often burdened by complicated silo-based business systems that hamper transportation operations (CORE, 2016; Francisconi, 2017). According to Tsiulin et al. (2017), in terms of in-city transportation and terminal operating, current problems are primarily related to massive urban sprawl and increased turnover of trade, lack of operational information and stakeholder acceptability. Ultimately, it affects planning (Vidal Vieira and Fransoo, 2015). These issues also work on the larger scale along the whole supply chain: last-mile delivery within municipality areas, hinterland, areas that belong to maritime ports (van Baalen et al., 2008). In addition, communication issues typically occur between private companies in and around ports, also including local authorities. The research by Vidal Vieira and Fransoo (2015) and Nordtømme et al. (2015) showed that problems with fleet and route planning, delay, damaged goods and theft, unsuitable terminal unloading and parking areas are partially connected to lack of cooperation between logistics service operators, local authorities and goods receivers.

Inefficient handling of cargo and containers throughout the whole supply chain is one of the major problems in the field. In particular, inefficient document management represents a serious burden for port management, thus, according to Groenfeldt (2017) and Kshetri (2018), standard vessel shipping involves dozens of parties (terminal operators, customs, shipping agents, port authorities, freight forwarders and etc.), having rounds of confirmations and regulations with more than a hundred of interactions between them (van Baalen et al., 2008; T-Mining, 2018). Part of the issue is caused by lack of awareness of upcoming transportation, i.e. notifying parties along the supply chain on arrival, cargo type, documentation checks, delays and accompanying information (Kshetri, 2018). In case of additional customs inspections, which happen on unpredictable manner and are poorly represented in digital format, the following delays significantly complicate the planned delivery and subsequent payment processes (Kuhrt, 2017; Kshetri, 2018; Smart Port, 2018). Another problem is a lack of cargo security, both in relation to theft and accidents where one company takes another's trailer or container by mistake. Commonly, a decent number of ports do not have any verification tools regarding identifying driver's permission to pick up the goods (T-Mining, 2018). This creates uncertainties as for recipient as well as for the sender, also affecting port's image.

A new technology called blockchain has emerged in recent years, a decentralized technology that is tightly connected to computer science (Qureshi, 2018). A key aspect of implementing blockchain is transparency and auditability of all transactions (Reyna et al., 2018). Decentralization excludes a party that is intermediary, meaning a central authority that keeps all data, verifies and authenticates transactions. Instead, blockchain can establish a direct connection between selected final users, providing communication as well as post 
factum actions (Antonopoulos, 2015). The technology is considered as the main tool that could shift out-of-date document management and decision-making processes to fully electronic format (Antonopoulos, 2015; Narayanan et al., 2016). Also, the technology is considered as a part of "Fourth Industrial Revolution", i.e. a tool from the concept of fully integrated manufacturing (Hofmann and Rüsch, 2017).

Currently, there is a number of cases where blockchain technology has been used, especially among big business and government. Blockchain technology has been mostly used in financial markets (Haferkorn and Quintana Diaz, 2015), and traditional banking services (Nguyen, 2016; Fanning and Centers, 2016; Swan, 2015) mainly by "reinventing" payments, financial services and economics (Antonopoulos, 2015; Haferkorn and Quintana Diaz, 2015). Notable, shortly after, blockchain started to be seen as a powerful tool for transforming many other industries: supply chain and logistics (O'Leary, 2017; Casino et al., 2019), healthcare (Swan, 2015), governance (Hou et al., 2018; Moura and Gomes, 2017), data management (Zhang et al., 2017; O'Leary, 2017), wildlife management (Dryga et al., 2019), etc. Even if blockchain is seen as trendy technology with very short history, its origins are in the 1990's (Chaum, 1993) during the dot-com era (Wright, 1997; Hwang et al., 2001). Current cryptocurrencies share plenty of similarities with "Ecash" (e.g. electronic wallet and digital coins), which was implemented in real transactions in USA and Europe. However, this currency did not survive with credit cards and ever-larger banks.

Evidently, within the rapid increase of blockchain initiatives in various industries, the literature lacks reviews that reveal the state-of-the-art applications in more specific, narrowed areas, e.g. maritime shipping, urban logistics, e-commerce delivery, other than overly presented general fields. Given the literature on the benefits in relation to supply chain and financial transactions, it appears that blockchain holds a potential to be used in shipping and maritime port logistics. Therefore, this paper aims to review the possible scenarios of distributed databases in port management and shipping.

Considering low maturity of the blockchain technology, lack of implementation experience and recently emerged academic interest, it is important to investigate how conceptually found projects relate or intersect with each other (Jabareen, 2009). Categorization is also of importance for further research possibilities. Each found scenario could be reviewed as a separate business case, devoted to a deeper, specifically focused analysis from business research perspective, as well as built architecture, stakeholders' interest and data security standpoint.

The purpose of the research is to categorize and characterize blockchain projects in shipping and supply chain management as well as the interrelations between them, including possible relations of findings to theoretical background and existing concepts. The focus is given to an overview of academic literature and already existing blockchainenabling applications (grey literature). Another objective is to deliver a better understanding of the reviewed literature' possible scenarios of usage. The research questions for this paper are as follows:

$R Q 1$. How does blockchain technology affect shipping and port logistics, and what are the possible scenarios of its implementation?

$R Q 2$. How do newly emerged blockchain projects refer to existing shipping concepts before the introduction of blockchain?

To answer the questions, the next section shortly presents the background, the technology and its particularities, distinguishing it from previous data management approaches. Thereafter, Section 3 presents the methodology. Section 4 summarizes the results and
Blockchainbased applications

203 
RIBS

30,2

204

develops business scenarios that all reviewed projects could be compiled to, also providing limitations and caveats that exist within the concept of distributed databases. Section 5 provides discussion on the results as well as the further research opportunities and open issues.

\section{Literature review}

\subsection{Fast-growing technology}

Before introduction of blockchain, a range of concepts has been proposed in the scientific literature to solve the problems of outdated document handling in the shipping environment. Part of them was investigated as single, short-term projects (CORE, 2016; Cassandra, 2011), whereas other have developed an extensive theoretical concept (EPCSA, 2011). Ultimately, the majority of them, such as CORE or Cassandra, follow the same goals and prioritize similar values.

For instance, the CORE project explored the best possible approach for secured data collection and distribution named "Supply Chain Visibility Tools" (CORE, 2016). The project focused on identifying accurate, complete and user-friendly data exchange and information management approach for all possible actors in the maritime industry: B2B, B2G and G2C. Both the CORE (2016) and the Cassandra (2011) project emphasized the lack of communication between shipping actors along the supply chain and accompanying risks. Insufficient information regarding who owns the goods and to whom they are sent to, is the main cause of potential uncertainties at the port after arrival. Lack of information makes each container's content unknown to terminal operator and port authorities, exponentially raising the chance for an unscheduled customs inspection and forwarding delays (CORE, 2016; Cassandra, 2011). Eventually, in terms of values and goals toward building an independent decentralized community system, such projects are identical to principles of further emerged blockchain and decentralized systems.

Similarly, but not identically, there has been a discussion around the concept of port community system (PCS), which is focused on solving the abovementioned communicational issue between multiple public and private stakeholders within maritime environment. PCS represents a central information hub (Figure 1), connecting shipment

Figure 1.

Communication between shipment actors without and with PCS-enabled
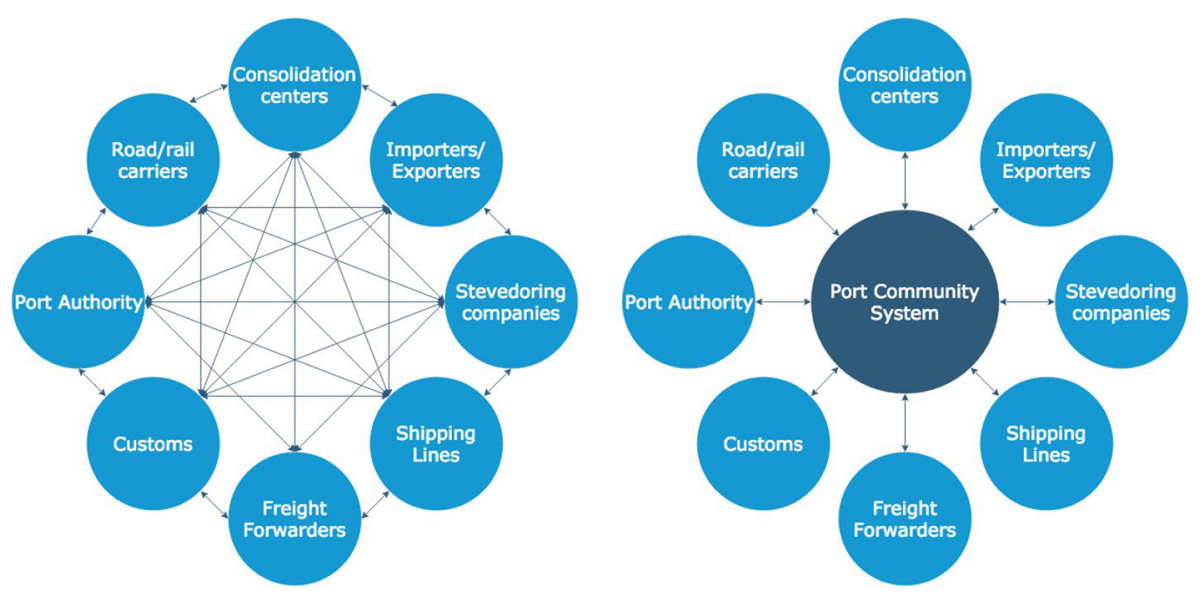

Source: Modified from van Baalen et al. (2008), Carlan et al. (2016), Rodrigue (2020) 
stakeholders (e.g. port authority, importers and exports, freight forwarder, customs, consolidation center) and the focus is on enabling intelligent exchange of information and documents (van Baalen et al., 2008; EPCSA, 2011; Francisconi, 2017). The main goal of PCS is to automate the complex information flows and redirect them to relevant parties, reduce the number of errors, processing costs and time delays.

Rodrigue (2020) in his book described the challenge of reaching a consensus between PCS involved stakeholders in terms of ownership and data security. Being a centralized actor, PCS's information flows should be regulated to protect port users from potential data monopoly or leaks. Another problem has been implementation of the concept, despite the overall attractiveness of potential benefits, has been hindered by the unwillingness of network partners to store information and share it, including the need of adjusting paper flow to new standards (van Baalen et al., 2008; Francisconi, 2017). The main inconsistence in agreements, however, appears to occur due to data security concerns. Further, such a system is dependent on a third-party actor, a mediator, i.e. central gatekeeper, more privileged in rights than other partners. Nevertheless, this is one of the conceptual attempts to shift document management, cooperation and decision-making processes to electronic format (Skwarek, 2017; Francisconi, 2017).

Considering previous attempts in simplifying maritime communication, blockchain has been promoted as an exact solution to the abovementioned issues related to communication, data security, elimination of the role of central gatekeeper, establishing point-to-point communication with transactions visibility and permissioned transparency.

Nowadays, the status of the majority of distributed database projects, however, is in "development" or "active testing". As for solutions, running applications mainly work as evoting platform or a database, show stable and successful results (Casino et al., 2019; Swan, 2015). This portrays a great sign of optimism toward its further development, marking a huge spark of public interest. According to Swan (2015), blockchain technology already gets a great importance in logistics and governance services, such as e-citizen services (Hou et al., 2018), national income distribution (Moura and Gomes, 2017), dispute resolution, and any kind of document registration e.g. marriage contracts, land agreements, etc. Moreover, there is a perspective for the usage of blockchain in healthcare (Hald and Kinra, 2019), with electronic healthcare records that allow patients to access their records regardless of the treatment center they were made in (Reyna et al., 2018; Swan, 2015). It does not only provide access, but a right for the patients to decide where the record information can travel. In this case, the entire control shifts from an institution to the patient, who is able either to delegate it or to move to another organization.

Moreover, a significant number of literature reviews is devoted to blockchain applications across a variety of industries, including reviews focused on technical characteristics of blockchain projects (Seebacher and Schüritz, 2017), interrelations with big data processes (Karafiloski and Mishev, 2017), feasibility of incorporating Internet of Things (IoT) and blockchain into existing databases (Conoscenti et al., 2016), healthcare and its influence on data sharing, managing health records and access control (Hald and Kinra, 2019), exploring the role of trust in sharing economies and hence the blockchain necessity (Hawlitschek et al., 2018).

Unlike the majority of the literature reviews on blockchain that intend to narrow the scope of the field, Casino et al. (2019) provided an extensive literature review using scientific and grey literature, which resulted in nine major categories: governance, integrity verification, financial, data management, business and industry, privacy and security, education, health, and internet of things. Although the authors carefully examine the papers, they overlook the linkage of projects between categories. In addition, such a review does not
Blockchainbased applications

205 
RIBS

30,2

206

go into detail of projects' core ideas, where their relations to any of the major categories are formal.

However, despite the increasing scientific attention, the technology is still poorly examined. The potential of the decentralized technologies is larger than what is currently implemented in solutions available on the market by the beginning of 2020, especially within the field of supply chain and shipping. The rest is not yet fully explored. A positive trend is seen through big companies' recent activities and blockchain related projects, such as Maersk, Alibaba, and Amazon (Groenfeldt, 2017; Kshetri, 2018; Casino et al., 2019). To understand the background of how blockchain holds a potential to transit current logistics system to a new level, it is necessary to focus on technology's fundamentals.

\subsection{Basic concept}

Blockchain technology is a distributed database that consists of identical data copies combined into blocks with decentralized type of storage (Seebacher and Schüritz, 2017). Seebacher and Schüritz defined it comprehensively as a distributed database based on peerto-peer network, which:

[...] consists of a linked sequence of blocks, holding timestamped transactions that secured by cryptography and verified by the network community. Once an element is appended to the blockchain, it cannot be altered, turning a blockchain into an immutable record of past activity (Seebacher and Schüritz, 2017, p. 14).

In contrast to centralized storage system, all permissioned actors are allowed to verify the state of the database - that it was changed according to protocol and all actors have the same views of the storage (Qureshi, 2018; Wüst and Gervais, 2017). In storage, each block keeps the data history of finished transactions (Figure 2). All transactions are confirmed by participants, and once a block is completed, it becomes unchangeable. Confirmed transaction represents a time-stamp, providing required information regarding when and how the transaction was completed (Wüst and Gervais, 2017).

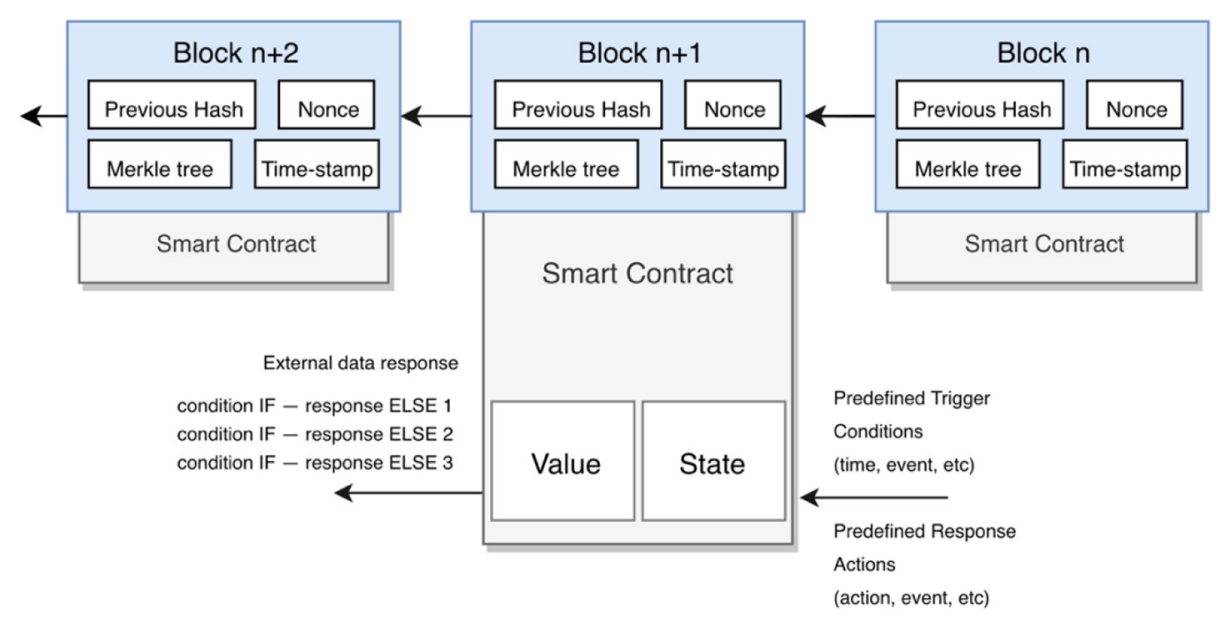

Figure 2.

An overview of blockchain architecture

Source: Modified from Yuan and Wang (2016), Bahga and Madisetti (2016) 
The risk of falsification is at minimum owing to storage decentralization and overall block dependency on each other (Hawlitschek et al., 2018; Seebacher and Schüritz, 2017). Each new block always refers to the hash of the previous one. Merkle Tree verification algorithm helps to check transactions' originality by splitting data into many hashing groups that were synchronized independently (Antonopoulos, 2015). The data are blocks is permanently synchronized and stored by actors and is available through either public or private type of blockchain. Being a decentralized peer-to-peer (P2P) network, public blockchain does not need intermediaries, to verify transactions and authenticate the source no central gatekeeper is required (Zalan, 2018; Reyna et al., 2018). However, for private system, if the intermediary is online, it may play a role of delegated actor for verifying and proceeding transactions. In case that it is offline, then it is responsible as a certificate authority (Wüst and Gervais, 2017).

To broaden the functionality, new blocks might be created through an automatic logic agreement approach, called smart-contracts. It can be abstracted as self-verifying, selfexecuting and self-response agreements in accordance with predefined logic that gets "activated" once predetermined circumstances are met (Narayanan et al., 2016; Yuan and Wang, 2016). Smart contract approach is held on "If - Else" basis, i.e. for any action there is a sequence of conditions to be checked by the algorithm. Then, depending on the check result, the transaction is completed or declined. Upon completion, the system transfers the transaction to the ledger (Yuan and Wang, 2016).

\section{Method}

The current study builds a conceptual framework for blockchain projects that exist within the field of shipping, port management and supply chain. According to Burkhart et al. (2011), the term "concept" is considered as an approach to systemize knowledge about a particular business approach. Conceptual framework has a variety of definitions and could be abstracted as a product of qualitative processes of theorization (Jabareen, 2009); a structure where natural progression of the selected phenomenon could be explained best in accordance with researcher's belief (Adom et al., 2018); or as an approach to better describe the relationships between several concepts (Jabareen, 2009). To build a conceptual framework, Jabareen (2009) suggests the following phases of research: defining data sources, categorizing the selected data, identifying the concepts, deconstructing and categorizing concepts, and overall concepts' integration and search for similarities.

Importantly, according to Adom et al. (2018), conceptual framework is used to describe close relationships between considered concepts in condition when existing theories are not applicable or do not exist. This could be crucial in relation to blockchain, considering the low maturity of the technology and lack of implementation results, even despite the recent high interest from the shipping industry and logistics, the quantitative data is still limited. In addition, the term of conceptual framework does not imply a collection of concepts, yet, rather, a construct in which each concept plays an integral role, thus developing the new understanding based on available information (Jabareen, 2009).

In the current research, the combination of Jabareen (2009) first phases of conceptual framework design and Grant and Booth's mapping review method are used. Study selection and concepts evaluation is explained further in the section.

\subsection{Projects and papers selection}

To address the set research questions, a literature review was carried out during January 2019 with subsequent update of the results during April 2019 and November 2019. For literature selection, we narrowed down the search criteria. Considering blockchain's low
Blockchainbased applications

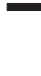


RIBS

30,2

208

maturity in the industry, the lack of quantitative results and implementation experience in particular, we did not focus solely on scientific literature, but rather applied a literature review with mixed type of sources: scientific and "grey literature." The search included the following scientific databases: Scopus, Web of Science, Google Scholar and Elsevier ScienceDirect. We also used additional search through the references of selected articles, i.e. "snowball search".

Having the focus on the current study to examine and categorize blockchain projects trends, we emphasize the importance of "grey literature" as the source, including commercial and startup projects. Relevant grey literature included mainly literature from private and public sector institutions/organizations: published research white-papers, reports and application descriptions of a particular commercial project, revealing the core idea of the project as well as the technical architecture. Further, as a large part of the blockchain development is driven by programmers, GitHub was also included as a search database. Among keywords, we used the following:

- ("blockchain” OR “dApp” (stands for "decentralized application)) AND ("maritime” OR "supply chain”) AND ("maritime” OR "port community").

\subsection{Study selection and evaluation}

At the stage of concepts selection, we decided to combine two reviewing methods: critical review and mapping review (Grant and Booth, 2009; Ridley, 2012). According to Kulviwat et al. (2004), critical review can be abstracted as a research aiming to synthesize material and critically evaluate its quality with a special emphasis on subject's conceptual innovations. Whereas mapping review is considered as a method to map out and categorize existing material on a certain issue (Gough et al., 2003). Both methods do not follow any particular quality assessment yet they are primarily focused on conceptual and graphical synthesis of material (Grant and Booth, 2009).

The search in scientific and grey databases returned 2120 results. Initially, all publications went through title and abstract check. After content check and excluding duplications and articles that did not comply with criteria (Table 1), the final number of included grey literature is 23 and 33 of scientific publications.

\begin{tabular}{lll}
\hline Selection criteria & Scientific database & Grey literature \\
\hline Inclusion: general & $\begin{array}{l}\text { Peer-reviewed conference, } \\
\text { journal papers, book chapters, } \\
\text { technical report etc. }\end{array}$ & $\begin{array}{l}\text { Whitepaper, technical report, commercial } \\
\text { proposal, application description and } \\
\text { guideline. }\end{array}$ \\
$\begin{array}{l}\text { Without restrictions } \\
\text { Inclusion: date range }\end{array}$ & $\begin{array}{l}\text { Mentioning of the project in scientific } \\
\text { literature }\end{array}$ \\
Exclusion: general & $\begin{array}{l}\text { Short papers, i.e. publications } \\
\text { including insufficient } \\
\text { explanation of the findings, or } \\
\text { primarily focusing on } \\
\text { technical aspects of blockchain }\end{array}$ & $\begin{array}{l}\text { Publications presenting insufficient } \\
\text { explanation of the concept; publications in } \\
\text { the form of news, interviews and discussion } \\
\text { papers }\end{array}$ \\
& - & $\begin{array}{l}\text { Projects lacking pilot demonstrations or } \\
\text { description of architecture }\end{array}$ \\
Exclusion: pilot availability & Publications not written in English \\
Exclusion: language & Publications not written in & \\
& English &
\end{tabular}

Table 1.

Inclusion and exclusion criteria

\section{English}


Literature, once selected, was carefully read, sorted out by the thematic content analysis and then divided into two research areas: supply chain and port management. To summarize results, it was decided to use tabular comparison type (Ridley, 2012) seen in Table 2.

Blockchain projects with exclusive focus on port management are indicated in "Focus filed" column by port management (PM), whereas projects that consider blockchain throughout the whole supply chain, including port activities, are indicated by supply chain (SC).

\section{Systematization of blockchain-based projects}

The current study aims to build a conceptual framework through a systematic review of 23 projects and 33 academic publications, representing recent scientific and grey literature. The purposes of the analysis are as follows:

- to provide an insight into relevant blockchain projects in supply chain with particular focus on port and shipping activities and

- to examine possible linkage between found projects in order to systematically analyze them with theoretical background and already existing conceptual frameworks.

For literature classification, we base our descriptive analysis on thematic area and main focus of found projects and their distribution over time.

Though we did not set a date range for literature search, the findings showed literature in the period between 2015 and April 2019 with the number increasing over the years (Figure 3). As such, the tendency is seen as it took several years for research community to start examining the blockchain's potential after its introduction as an international financial solution. It is worth noting that during 2018 and 2019, the number of journal publications has increased dramatically, which could be explained by a growing academic interest in the

Project Focus field Case study $\quad$ Year of start Project type Key functionality

Source: Modified from Ridley (2012)
Blockchainbased applications

209
Table 2.

Tabular source comparison method

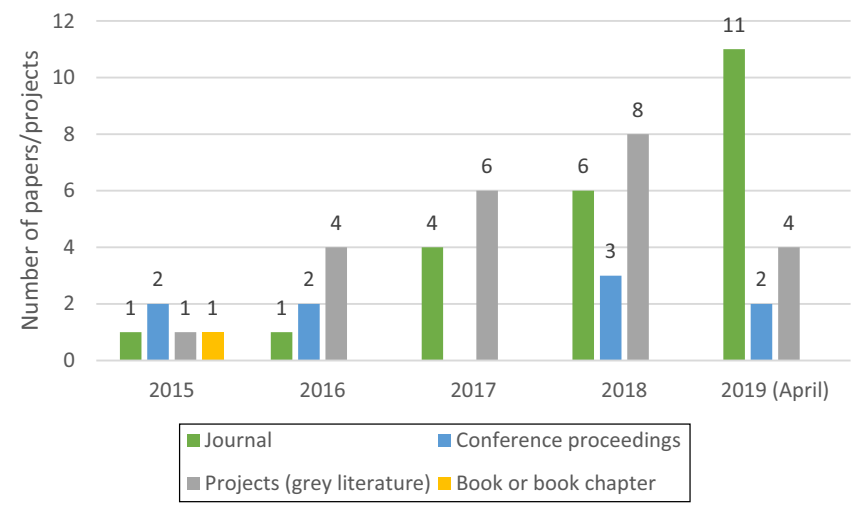

Figure 3.

A year-wise analysis of selected literature per publication type 
RIBS

30,2

210

research community and rapidly-evolving nature of the technology itself. However, specifically in 2019 up to April, the search did not show a variety of newly founded blockchain projects from grey literature, which could be possibly explained by market and competition stabilization. Also, a certain number of startup companies later was absorbed or affiliated with the industry majors, e.g. T-Mining as a project of Port of Antwerp; TradeLens as a side-project of Mærsk (Safety4sea, 2018).

The findings of reviewing 33 academic publications indicate that 20 publications $(60.6 \%)$ focus on technical characteristics of blockchain (especially those published in 2015, 2016 and 2017), as well as the state-of-the-art of the considered topic, in particular supply chain, exploring opportunities and challenges in relation to potential blockchain implementation. The insights in regard to maritime port management and shipping are barely presented, usually covered as one of supply chain's sub-topics. Considering low maturity of the technology and recent academic interest, publications on concepts have emerged mostly from 2018 and onwards, showing nine papers in total $(27.3 \%)$. Technical architecture and new blockchain protocols were proposed in three $(9 \%)$ publications, while new consensus algorithms were met only in one paper $(3 \%)$. As for selected projects, they are shown in Table 3. In general, the majority of them, including start-ups, find motivation in creating tools for tracking goods and product data, including the place of its origin (Casino et al., 2019; Groenfeldt, 2017; Kshetri, 2018; Provenance, 2018). In this case, blockchain represents a global ledger, available for tracking throughout the whole transportation process from start to end. Thus, according to Provenance (2018), Huang (2018) and Higgins (2017), it will help to gain credibility from the final customer as well as from side partners by showing the information in real-time: the manufacturer country, transportation time, time spent in warehouse and temperature requirements. This is the point where big companies such as Amazon and Alibaba are aiming for (Kshetri, 2018; Swan, 2015). For example, Provenance (2018) started as a pilot project in the fishing industry to allow users to monitor the date of catching, transportation chain and storage conditions, thus the customer can make an educated conclusion about the product quality and its freshness. The tendency is described by the overall digitalization and IoT approach of device connectivity (Ford, 2018; Kshetri, 2018; Skwarek, 2017; Bahga and Madisetti, 2016).

As for the supply chain and logistics, there is a number of ongoing projects that are worth closer attention. One of the largest blockchain projects was launched by the Danish shipping company Maersk in collaboration with IBM (Tradelens, 2019). The goal is to create a tool to speed up supply chain and paper-based processes. The vision is to trace goods more efficiently and to reduce the volume of overall point-to-point communications. It digitalizes the workflow, tracks end-to-end shipments, and eliminates frictions as well as uncertainties in real-time (Groenfeldt, 2017; Tradelens, 2019; T-Mining, 2018). For example, once customs authorities sign shipping documents, they are transferred to the database along with their digital signature. It is planned that digital signatures will fully replace their physical analogues. This certifies a completed process to all involved actors, including Maersk and government representatives, which in turn simplifies work with disputes (each transaction is unchangeable) and further communication (Pournader et al., 2019).

Besides the abovementioned companies, there are other organizations, mostly startup companies, that aim to build similar blockchain platforms for product tracking in supply chains of several products and services (Huang, 2018; Wang et al., 2018, 2019). For instance, projects Modum, Gemalto, and Chronicled (Kshetri, 2018) tend to control temperature requirements during transportation process and reduce the amount of paperwork as well as work with disputes for pharmaceutical industry. Everledger is targeting to manage the supply chain throughout the whole route, including production information (Casino et al., 2019; Kshetri, 2018). In the next subsections, we compile literature by the key areas that listed projects are focused on. 


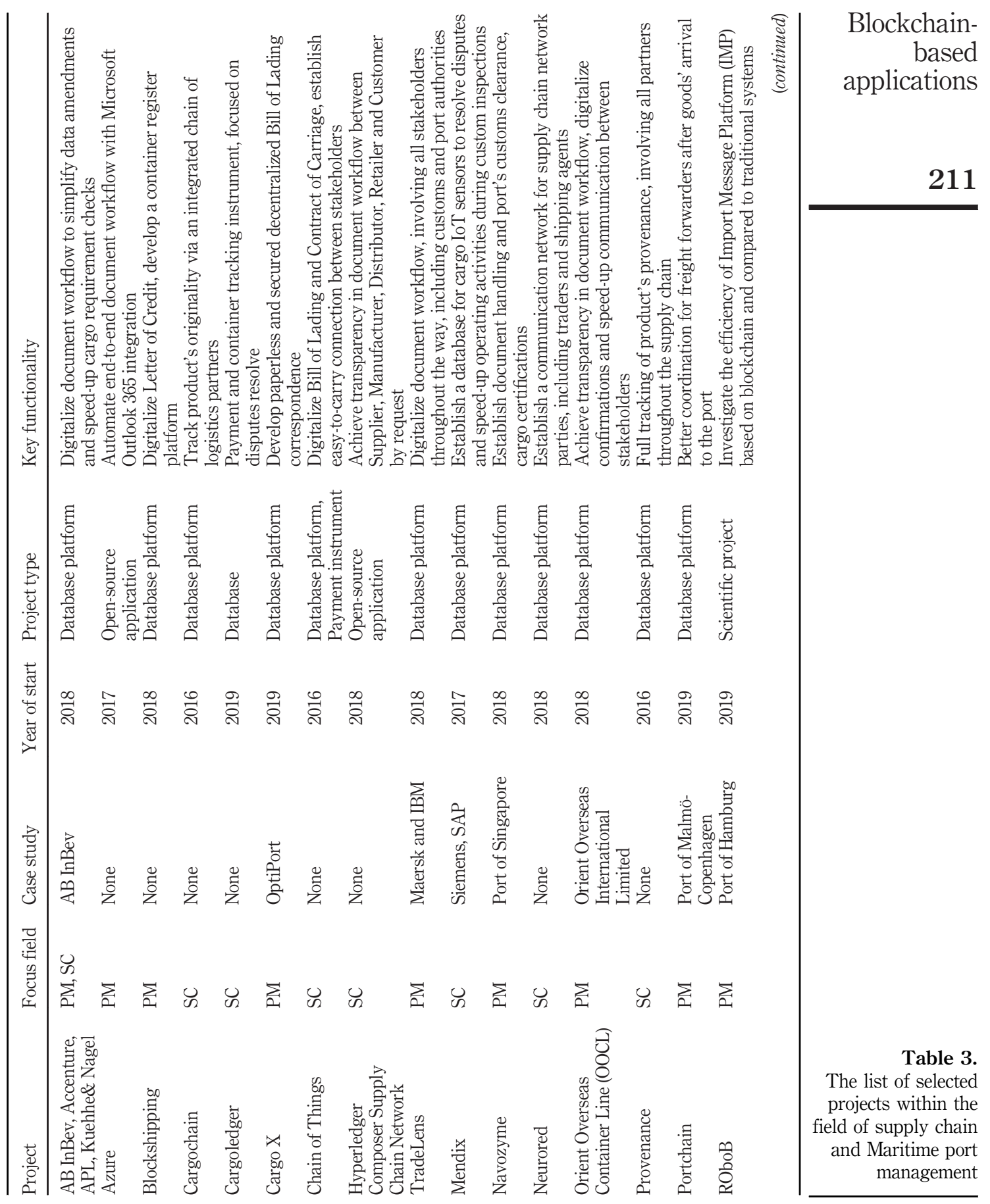




$$
\begin{aligned}
& \text { RIBS } \\
& 30,2
\end{aligned}
$$

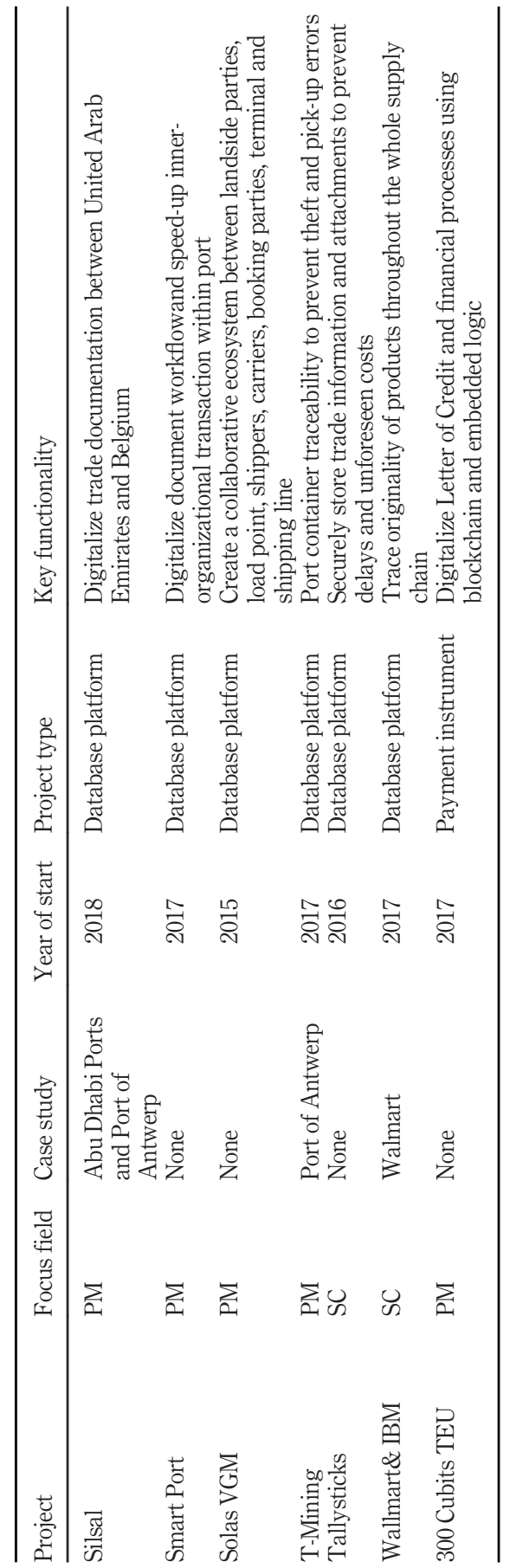

Table 3. 


\subsection{Interrelations between reviewed projects}

By analyzing the selected projects from Table 3 through projects' proposals, white papers, technical architecture and reports, we find that in terms of conceptual interrelations, all reviewed projects can be classified into three areas:

(1) projects designed to simplify and speed-up document workflow (document workflow management);

(2) projects designed to speed-up financial transactions throughout the delivery after goods arrival to the terminal (financial processes); and

(3) projects designed to improve communication at the maritime port area and to connect all supply chain parties starting from the place of product's origin (device connectivity).

Projects showed clear interlinkages where certain projects could be simultaneously compiled into more than one area. Moreover, none of the reviewed projects consider all three areas at once. Figure 2 provides a perceptive analysis of reviewed projects and their associated areas. Each circle represents one area. When circles superimpose on each other, the projects in between imply more than one described area (Figure 4).

Overall, a significant number of projects from each field could be found, including the ones that superimpose more than one area. The highest number of projects is focused on categories of document workflow and device connectivity, having nine and four projects. respectively. There are, however, only two projects focused exclusively on financial processes. Specifically, the commercial interest shifts towards compiling the digitization of paper workflow and financial transactions into one single application or project. On the

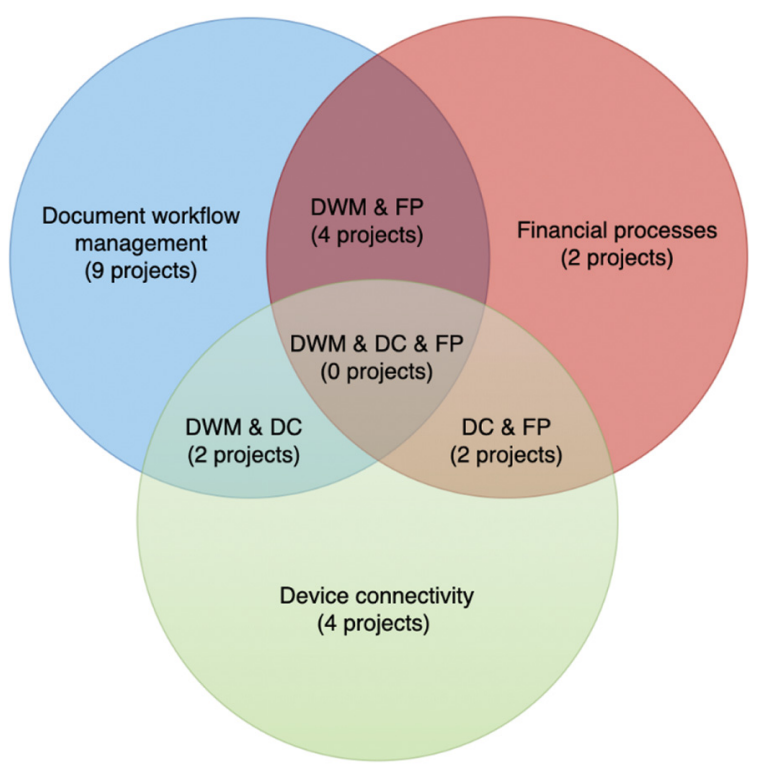

Notes: DWM: Document workflow management; FP:

Financial processes; DC: Device connectivity

Figure 4.

Distribution of projects across the conceptual frameworks 
RIBS

30,2

other hand, financial aspects of blockchain could poorly exist without any reasonable document transaction basis.

Globalization confidently pushes the market towards digitalization through a variety of concepts within the scope of Internet of Things and how to connect them around supply chain, and extending the functionality for final customer as well as for manufacturer. As it is portrayed on the figure, the projects of device connectivity rarely intersect with other areas, leaving just four projects in total. Also, it is important to note, there is no concept combining all of the described areas at once.

\subsection{Document workflow management}

Paperwork flow in shipping represents a sequence of information and goods documentation, moving from one party to another. Within each additional stage of paperwork along the transportation way, the risk of falsification, miscommunication and delay increases (Swan, 2015). The whole paper flow goes through rounds of regulations and confirmations, regularly completed using e-mail, telephone call, fax or using a relevant ERP module (Tradelens, 2019; Azure, 2018). The flow can include documents such as Bill of Lading, Customs Declaration, transportation information and other papers related to shipment (Francisconi, 2017). Each document is proceeded through numerous interactions with more than dozens of parties being involved on average: terminal operators, customs, port authorities, freight forwarders and many more (T-Mining, 2018). The time taken on each document process is always unpredictable due to the lack of awareness between parties and additional inspections that are poorly represented in digital format, often happen in an unexpected manner. Such circumstances highly reduce further transportation efficiency of goods as well as increasing the vehicle's idle time at the port.

The underlying principle of blockchain in document workflow is, when integrated, the process of data transfer to the blockchain can be executed digitally instead of the conventional physical flow. Partners are internal nodes, have identical copy of the database, and are able to contribute to the process by approving the documentation online. Approvals are seen as timestamps throughout the process, thus showing the exact time, place and condition of the transaction. Once the required approval has been received, smart contracts as internal logic could help to pass documentation to the next parties automatically. History of document handling is visible to parties, being immune to unauthorized changes. Blockchain's fundamentals such as transparency of actions and consensus algorithm increase the overall attractiveness and trust between partners. It helps to decrease the occurrence of fraud. Trust and flexibility are achieved through ability to track any changes in the ledger in real-time. Any suspicious actions are automatically rejected by the nodes due overall chain connectivity.

It works similarly in warehousing. Inventory needs quality certifications, involving experts with signatures and notarized documents as a part of authentication (Kuhrt, 2017). When documents are crosschecked, cargo is ready for shipping. By combining inventory transaction with a quality document, blockchain using internal logic can solve the problem of traceability and keeping records, streamlining the whole paperwork along the transportation.

\subsection{Financial processes}

Financial process scenario regards to the payment to a consigner bank so that cargo can be released from the terminal area. Financial flows could be barely generalized since each shipment is attached to a chosen Incoterms regulation, i.e. an obligation of buyers and sellers in foreign trade contract (Francisconi, 2017; EPCSA, 2011). Depending on the chosen 
regulation type, certain parties could be restricted from taking the goods until the consigner bank appropriately checks the payment in accordance with "Letter of Credit" that goes along with the cargo. The goods leave the terminal area only when all the information is clarified and payments are cross-checked. Such procedure typically causes delays since a consigner bank does not belong to port's internal community or communicational system, and thus cannot be notified of the status of the container in real time or receive documentation. Once everything meets bank's requirements, the payment is done and container is taken to further transportation by carrier or freight forwarder (Francisconi, 2017).

Additionally, customs inspections cause extra delays, which happen due to unexpected selection basis. These factors, along with the lack of up-to-date information from consigner bank, makes the calculation of the average time spent at the terminal inconsistent and inaccurate. Commonly, the delay happens within the time when the ship is unloaded and cargo is ready for further transportation yet stopped unless the payment transactions and details are cross-checked by the bank and the port (Casino et al., 2019; Kshetri, 2018; Francisconi, 2017).

For the blockchain scenario, the crucial point is to enable trusted and secured information flow between the consigner bank and the port network. In this case, once notified regarding unloading of the container, a consigner bank, being one of the nodes in the network, starts a cross-check of all required documentation, keeping to a minimum the number of point-topoint communications thus speeding up the pick-up for a freight forwarder. In this case, payment orders are automated through smart contracts, notifying the client regarding the status of goods. Moreover, the ability for other parties to track the approval of payment documents and follow the process in real time can pose a great impact on overall processing time. Awareness is required for proceeding with the payment when documents pass the checking procedures, i.e. proof of commercial viability (CORE, 2016; Blockshipping, 2018).

\subsection{Iot and device connectivity}

Internet of Things and overall device's connectivity are among the key concepts addressed by the reviewed projects. Gradually, the whole transportation and supply chain process shift towards transparency and traceability as a way to better demonstrate the quality of the product, its origins. Besides, such detailed transportation history might be applied in disputes resolution between certain parties throughout the way. Internet of Things functionality, once embedded, provides a broader list of trackable real-time characteristics: location, temperature, capacity, movement, damage (Minoli and Occhiogrosso, 2018).

Blockchain in this regard can play a role of a database, updated in real time by multiple actors. Goods transportation records are automatically sent to blockchain as timestamps once the agreed checkpoints are passed (Tradelens, 2019; Tallysticks, 2018; Provenance, 2018). It allows to monitor precise location, condition and other needed parameters in order to monitor goods on the way. Apart from that, the embedded logic is able to define whether parameters taken from sensors go beyond the required level and create a report accordingly (Skwarek, 2017). In this case, the information is stored automatically without any manual user input, visible to prior-agreed parties in the network. Such approach helps to spend less time on resolving disputes and prevent fraud, knowing precisely "when and where" each of action is going to occur (Casino et al., 2019; Kshetri, 2018). The usage of smart contracts promotes the utilization of automatic logic for creation of self-made reports and notifications not only for the sender but also for all parties involved. The end result will not only facilitate the reduction in the average time spent on resolving disputes and transparency improvements, but will help to achieve better trust from the final customer as well

Blockchainbased applications 
RIBS

30,2

(Bahga and Madisetti, 2016; Swan, 2015). A great number of projects (Cargochain, 2018; Ford, 2018; Reyna et al., 2018; Provenance, 2018) demonstrate this as a main new feature for the final customer. For instance, continuous location tracking allows the customer to make an educated conclusion about the product's quality.

In addition, blockchain might be also used exclusively within the port area for security reasons. For instance, to prevent cargo theft confirmation is required from the blockchain ledger so that freight forwarder can be allowed to pick up goods once he receives the digital approval from other parties and the system, verifying driver's permission details. By using the driver's digital profile or QR code, the driver receives an approval and is then able to carry the container. The security mechanism is achievable through main principles of decentralized storage: immutability to changes and high diversity of users, including their possible wide allocation.

\section{Discussion}

Current section presents a discussion on the collected data from analyzed literature in relation to proposed research questions.

\subsection{RQ1. How does blockchain technology affect shipping and port logistics and what are the possible scenarios of its implementation?}

For the search of this review, having no particular date range set, all literature is dated between 2015 and April 2019 with the number of journal publications and projects increasing over the years. Considering that blockchain technology is new and just entering the field of shipping and supply chain, selected publications were identified as suitable. The sample consisted of 33 academic publications, out of which only nine papers $(27.3 \%)$ present interpretation of blockchain being adopted in the field of supply chain with narrow or no particular focus on shipping. Simultaneously, grey literature in the form of commercial projects focused specifically on blockchain in shipping showed a variety of conceptual frameworks, which can be generalized into three scenario-categories: document workflow management, financial processes and device connectivity. Certain projects imply several described scenario-categories, while none of the projects consider all three scenarios at once.

Interestingly, across scientific literature, a few reviews are devoted to blockchain applications in supply chain management and shipping. These also inspired the current research. As such, Kshetri (2018) provided an overview of the largest initiatives by IT companies towards blockchain. Having insights into general description of each IT majors' blockchain initiatives (Amazon, Alibaba, Microsoft, IBM), the publication stayed in frames of general description without considering common dynamics, focusing exclusively on business cases. Another publication, Francisconi (2017) contributed with the own design of blockchain business cases in the supply chain and shipping, highlighting four. One of these cases, specifically "IoT and smart contract automatization", does not fully reflect the business scenario and implies more of a technological advance description up to the date. Another noticeable drawback is a lack of attention to potentials of blockchain at the port site, i.e. for pick-up control and port gate monitoring.

The gradually growing number of publications, however, indicates not only a rising interest from academic community to the topic of blockchain in shipping, but also how academic literature lags behind the commercial industry and start-ups, whose projects are actively developing and proposing new solutions to the market of logistics. As such, the scenario of document workflow management and its combination with two other categories seemed the most demanded and competitive by the April 2019, showing 15 projects in total. The main motivation of it is to renew the outdated way of document handling between the 
parties of supply chain and within the port operations in particular. Though in the past there have been many attempts to overcome the barriers with lack of trust, information security, miscommunication and data falsification, blockchain due to its technical features seems the only existing tool that is able to solve such problems.

Nevertheless, the concept of document workflow digitalization has its limitations. While current communication is mostly based on physical paper exchange, fax, usage of different accounting systems and scanned copies, the creation of partners' network and shifting the workflow to new and digitalized formats might bring serious adoption problems. If having such a system set and stably working, the engagement of transportation parties might create practical barriers and misunderstanding. A significant change to parties' business routine could be rejected as it would bring additional costs related to HR and IT support (Tsiulin et al., 2017; Lindholm, 2010).

In addition to the scenario of document handling inwards and outwards of the port area, the technology might have a significant contribution to inner-port organizational processes: port gate queuing, trailer or container security, etc. Overall, according to reviewed projects, the following processes and actions within the port can be modernized by using blockchain:

- terminal cargo allocations,

- terminal transactions,

- document work flow tracing,

- inventory certifications and

- cargo handling accessibility.

Other two scenarios, financial processes and device connectivity, respectively, also bring a great potential to the shipping industry. Io T represents great benefits in the long-term perspective. Being a consequence of globalization, the whole industry of mass technologies, including IoT's components, become cheaper within time than they had initially appeared on the market and thus financially affordable. Consumer demand and proportionally decreasing prime costs motivate companies to spread it further, providing better service availability. It leads to a moment when adding IoT features will not add significant costs to transportation.

On the other hand, the concept of financial processes is mostly debated in terms of law regulation. First, global supply chain operates in an environment where involved parties are required to follow policy rules and regulation. Because all financial transactions in blockchain use alternative money - "cryptocurrency" - there is no direct evidence from government supporting such payment method, even though it shows a lot of advantages in a sense of operations velocity and commissions prices. However, cryptocurrency is still seeking for governmental support, which makes it difficult to attract capital and investments for ongoing projects. Among all countries, in 2018 only Japan (Graham, 2017), Estonia (Shome, 2017) and Belorussia (Higgins, 2017) declared it as a financial instrument, thus creating difficulties not just in transactions between companies from different countries, but even within one administrative region.

Commonly, blockchain projects aim for fund raising by creating Initial Coin Offering (ICO), an analog of initial public offering in stock structure, when tokens (similarly to stocks) are distributed among participants for a fixed value (Haferkorn and Quintana Diaz, 2015). In this way, each blockchain project from financial area creates a dependence of its own internal currency and mining process. Figuratively speaking, such potential project further represents a role of "Local Central Bank", which can be shown as "a way to shy away from their direct commitment - creating an application” (Kasireddy, 2017).
Blockchainbased applications 
RIBS

30,2

218

\subsection{RQ2. How do newly emerged blockchain projects refer to shipping concepts existed}

before the introduction of blockchain?

An interesting linkage could be traced between the concepts of blockchain in document workflow management and Port Community System. Based on the same network of stakeholders, both concepts follow a goal to digitalize shipping documentation and make the communication along the supply chain parties more unified and flexible. However, according to the literature (van Baalen et al., 2008; EPCSA, 2011; Skwarek, 2017), PCS is presented as a platform with a concrete type of ownership. Moreover, throughout the literature it is not always clear how the system is established, whether PCS is owned by a public or private organization, and how does it regulate the data confidentiality concerns. The centralized role of PCS does not protect involved parties from data leakage, yet it becomes a mediator i.e. "a central gatekeeper" between all stakeholders, more privileged in rights than other parties.

A blockchain embedded into the shipping document workflow differs from PCS primarily because the data is spread across all participants as well as the consensus rights. Each party is able to see the history of document's records and digitally "sign" it once the predefined conditions are met. Thus, the blockchain could solve the problem of PCS: decentralization of blockchain leaves no party as a data monopolist, and technically the data is safe due to blockchain's hash verification algorithms (data blocks connectivity). What also speaks in favor to the technology is the viability of blockchain startups, their continuous focus on further development being covered with financial support, whereas business cases with PCS do not have a wide practical experience and are only considered as theoretical concepts.

Nevertheless, there are several variations of the port community network that vary by the ownership base, involved parties, architecture and other parameters. In academic literature these concepts are all scattered around the term of PCS. A closer analysis of these concepts as well as relationship between them could reveal a deeper linkage with current blockchain initiatives, which will be our primary area for the further research. A big role will be also dedicated to the role of trust and to what extent the trust is important within current state of shipping transportation and at the port area in particular.

As for research limitations, it is worth noting that this review cannot be seen as exhaustive since the technology is new and developing continuously. Also, the interest to the topic from the scientific community is only at its initial state and is rapidly expanding over the years. That was one of the main reasons to dedicate a significant part to grey literature, which is more representative in terms of application development than academic publications at the moment. Also, although blockchain shows high potentials for innerorganizational maritime port systems, considered projects show a lack of technical data and final case results. Due to commercial nature and incompleteness of projects, it complicates further in-depth analysis of numerical efficiency blockchain can be measured in practice. At the same time, the scarcity of blockchain research that quantify the blockchain impact on the logistics operations, including maritime transportation, could not enable the analysis the results from operation management point of view.

\section{Conclusion}

The main aim of this paper was to develop a literature review on blockchain in shipping and supply chain. The sample selection of 56 literature sources (23 projects and 33 publications) follows a goal to build a conceptual framework and to review how blockchain can affect communication between involved stakeholders, information flow, data confidentiality concerns and other processes related to shipping and port management. Also, if selected 
projects have interlinkages in between themselves and whether the technology can be integrated into existing maritime freight information system.

Reviewed projects showed considerable shifts made towards paper flow digitalization and a clear tendency to link blockchain and Internet of Things, integrating technology into current data management systems. The selected projects can be clearly distinguished into the three main areas by their commercial and conceptual interest: document workflow management, financial processes and device connectivity. Concepts associated with blockchain and document paper framework got a broad support among the reviewed projects, also indicating a potential from scientific perspective. However, having clear interlinkages, none of reviewed projects considered all three defined areas at once.

Our findings indicate that unintendedly, current initiatives follow similar priorities as projects that had existed before the term of blockchain has been discovered, for instance the concept of Port Community System. The difference with blockchain is that within Port Community System no technical solution was available that could implement declared values of transactions' transparency, auditability and real-time functional equity.

From aspects of practical implications, this work is of great help for port authorities and port-based companies, including hinterland authorities, to obtain awareness, categorization as well as characteristics, strengths and weaknesses of current blockchain initiatives within the area.

As for future research opportunities, it became clear that an impulse of interest to blockchain is supported by commercial enterprises as well as by scientific community. Concerning further research opportunities, there is a potential in getting a deeper understanding of architecture of the port inner-organizational system with blockchain being implemented. Also, establishing a clear communication map between parties, developing key performance indicators and revising existing business models can reveal a way of how distributed systems could be developed towards more efficient port management operations.

\section{References}

Adom, E., Dickson, J. and Hussein, A.-A. (2018), "Theoretical and conceptual framework: mandatory ingredients of a quality research", International Journal of Scientific Research, Vol. 7, pp. 438-441.

Antonopoulos, A.M. (2015), Mastering Bitcoin: Unlocking Digital Cryptocurrencies, O’Reilly Media.

Azure (2018), "Azure - blockchain-supply-chain-solution", Github, available at: https://github.com/ Azure/blockchain-supply-chain-solution (accessed 18 March 2018).

Bahga, A. and Madisetti, V. (2016), "Blockchain platform for industrial internet of things", Journal of Software Engineering and Applications, Vol. 9 No. 10, pp. 533-546, doi: 10.4236/jsea.2016.910036.

Blockshipping (2018), "Blockshipping's GSCP ICO - transforming the global container shipping industry", available at: www.blockshipping.io/ (accessed 13 December 2018).

Burkhart, T., Krumeich, J., Werth, D. and Loos, P. (2011), "Analyzing the business model concept - a comprehensive classification of literature", International Conference on Information Systems 2011, ICIS 2011, p. 5.

Cargochain (2018), "Domschiener/Cargochain”, Github, available at: https://github.com/domschiener/ cargochain. (accessed March 19 2018).

Casino, F., Dasaklis, T.K. and Patsakis, C. (2019), "A systematic literature review of blockchain-based applications: current status, classification and open issues", Telematics and Informatics, Vol. 36, pp. $55-81$.

Cassandra (2011), "Cassandra”, available at: www.cassandra-project.eu/mainmenu/about-cassandra. html (accessed 12 June 2018).
Blockchainbased applications 
RIBS

30,2

Chaum, D. (1993), "Numbers can be a better form of cash than paper", in Preneel, B., Govaerts, R. and Vandewalle, J. (Eds), Computer Security and Industrial Cryptography. Lecture Notes in Computer Science, Vol. 741, Springer, Berlin, Heidelberg.

Conoscenti, M., Vetro, A. and De Martin, J.C. (2016), "Blockchain for the internet of things: a systematic literature review", 2016 IEEE/ACS 13th International Conference of Computer Systems and Applications (AICCSA) IEEE, pp. 1-6.

CORE (2016), "The core project European project CORE”, available at: www.coreproject.eu. (accessed 17 March 2018).

Dryga, A., Tsiulin, S., Valiavko, M., Qing, Y. and Reinau, K.H. (2019), "Blockchain-based wildlife datamanagement framework for the WWF bison rewilding project", ICBIS 2019 conference, Bejing, pp. $62-66$.

EPCSA (2011), "How to develop a port community system European port community system association", available at: www.unece.org/fileadmin/DAM/trade/Trade_Facilitation_Forum/ BkgrdDocs/HowToDevelopPortCommunitySystem-EPCSAGuide.pdf (accessed 10 February 2016).

Fanning, K. and Centers, D.P. (2016), "Blockchain and its coming impact on financial services”, Journal of Corporate Accounting and Finance, Vol. 27 No. 5, pp. 53-57.

Ford, N. (2018), "IoT application using Watson IoT and IBM blockchain mendix", available at: www. mendix.com/blog/built-iot-application-10-days-using-watson-iot-ibm-blockchain/ (accessed 19 March 2018).

Francisconi, M. (2017), “An explorative study on blockchain technology in application to port logistics”, Master Thesis, Delft University of Technology.

Gough, D., Kiwan, D., Sutcliffe, K., Simpson, D. and Houghton, N. (2003), A Systematic Map and Synthesis Review of the Effectiveness of Personal Development Planning for Improving Student Learning, EPPI-Centre, Social Science Research Unit, London.

Graham, L. (2017), "How Japan is fast becoming the powerhouse of the bitcoin market CNBC", available at: www.cnbc.com/2017/09/29/bitcoin-exchanges-officially-recognized-by-japan.html. (accessed 18 March 2018).

Grant, M. and Booth, A. (2009), "A typology of reviews: an analysis of 14 review types and associated methologies”, Health Information and Libraries Journal, Vol. 26 No. 2, pp. 91-108, doi: 10.1111/ j.1471-1842.2009.00848.x.

Groenfeldt, T. (2017), "IBM and maersk apply blockchain to container shipping Forbes", available at: www.forbes.com/sites/tomgroenfeldt/2017/03/05/ibm-and-maersk-apply-blockchain-to-containershipping/ (accessed 19 March 2018).

Haferkorn, M. and Quintana Diaz, J.M. (2015), Seasonality and Interconnectivity within Cryptocurrencies - An Analysis on the Basis of Bitcoin, Litecoin and Namecoin, Springer International Publishing, Cham, pp. 106-120.

Hald, K.S. and Kinra, A. (2019), "How the blockchain enables and constrains supply chain performance", International Journal of Physical Distribution and Logistics Management, Vol. 49 No. 4, pp. 376-397.

Hawlitschek, F., Notheisen, B. and Teubner, T. (2018), "The limits of trust-free systems: a literature review on blockchain technology and trust in the sharing economy", Electronic Commerce Research and Applications, Vol. 29, pp. 50-63.

Higgins, S. (2017), "Walmart: blockchain food tracking test results are 'very encouraging' Coindesk", available at: www.coindesk.com/walmart-blockchain-food-tracking-test-results-encouraging/. (accessed 29 January 2018).

Hofmann, E. and Rüsch, M. (2017), "Industry 4.0 and the current status as well as future prospects on logistics", Computers in Industry, Vol. 89, pp. 23-34, doi: 10.1016/j. compind.2017.04.002. 
Hou, J., Wang, H. and Liu, P. (2018), “Applying the blockchain technology to promote the development of distributed photovoltaic in China", International Journal of Energy Research, Vol. 42 No. 6, pp. 2050-2069.

Huang, E. (2018), "Blockchain could fix a key problem in China's food industry: the fear of food made in China quartz", available at: https://qz.com/1031861/blockchain-could-fix-a-key-problem-inchinas-food-industry-the-fear-of-food-made-in-china/ (accessed 29 January 2018).

Hwang, M.-S., Lin, I.-C. and Li, L.-H. (2001), “A simple micro-payment scheme”, Journal of Systems and Software, Vol. 55 No. 3, pp. 221-229.

Blockchainbased applications

Jabareen, Y. (2009), "Building a conceptual framework: philosophy, definitions, and procedure", International Journal of Qualitative Methods, Vol. 8 No. 4, pp. 49-62.

Karafiloski, E. and Mishev, A. (2017), "Blockchain solutions for big data challenges: a literature review", 17th IEEE International Conference on Smart Technologies, EUROCON 2017 Conference Proceedings, pp. 763-768.

Kasireddy, P. (2017), "Fundamental challenges with public blockchains medium", available at: https:// medium.com/@preethikasireddy/fundamental-challenges-with-public-blockchains-253c800e9428 (accessed 18 March 2018).

Kshetri, N. (2018), "Blockchain's roles in meeting key supply chain management objectives", International Journal of Information Management, Vol. 39, pp. 80-89.

Kuhrt, T. (2017), "Requirements: use-cases:use-case-supply-chain-logistics wiki Hyperledger", available at: https://wiki.hyperledger.org/requirements/use-cases/use-case-supply-chain-logistics (accessed 17 March 2018).

Kulviwat, S., Guo, C. and Engchanil, N. (2004), "Determinants of online information search: a critical review and assessment”, Internet Research: Electronic Networking Applications and Policy 2004, Vol. 14 No. 3, pp. 245-253.

Lindholm, M. (2010), "A sustainable perspective on urban freight transport: factors affecting local authorities in the planning procedures", Procedia - Social and Behavioral Sciences, Vol. 2 No. 3, pp. 6205-6216.

Minoli, D. and Occhiogrosso, B. (2018), "Blockchain mechanisms for IoT security", Internet of Things, Vol. 1-2, pp. 1-13, doi: 10.1016/j.iot.2018.05.002.

Moura, T. and Gomes, A. (2017), "Blockchain voting and its effects on election transparency and voter confidence", Proceedings of the 18th Annual International Conference on Digital Government Research, $A C M$, pp. 574-575.

Narayanan, A., Bonneau, J., Felten, E., Miller, A. and Goldfeder, S. (2016), Bitcoin and Cryptocurrency Technologies: A Comprehensive Introduction, Princeton University Press, Princeton.

Nguyen, Q.K. (2016), "Blockchain-a financial technology for future sustainable development", Proceedings - 3rd International Conference on Green Technology and Sustainable Development, GTSD 2016, pp. 51-54.

Nordtømme, M.E., Bjerkan, K.Y. and Sund, A.B. (2015), "Barriers to urban freight policy implementation: the case of urban consolidation center in Oslo", Transport Policy, Vol. 44, pp. 179-186.

O'Leary, D.E. (2017), "Configuring blockchain architectures for transaction information in blockchain consortiums: the case of accounting and supply chain systems", Intelligent Syst. Acc. Finance Manage, Vol. 24 No. 4, pp. 138-147.

Pournader, M., Shi, Y., Seuring, S. and Koh, S.C.L. (2019), "Blockchain applications in supply chains, transport and logistics: a systematic review of the literature", International Journal of Production Research, Vol. 58 No. 7, pp. 1-19.

Provenance (2018), "Blockchain: the solution for supply chain transparency provenance", available at: www.provenance.org/whitepaper (accessed 30 January 2018).

Qureshi, H. (2018), "Haseeb Qureshi - freecodecamp medium freecodecamp”, available at: https:// medium.freecodecamp.org/@hosseeb. (accessed 9 April 2018). 
RIBS

30,2
Reyna, A., Martín, C., Chen, J., Soler, E. and Díaz, M. (2018), "On blockchain and its integration with IoT. Challenges and opportunities”, Future Generation Computer Systems, Vol. 88, pp. 173-190, doi: 10.1016/j.future.2018.05.046.

Ridley, D. (2012), The Literature Review: A Step-by-Step Guide for Students, SAGE Study Skills.

Rodrigue, J.-P. (2020), “Routledge, New York, 456 pages”, ISBN 978-0-367-36463-2.

Safety4sea (2018), "Port of Antwerp works on blockchain pilot project - SAFETY4SEA", available at: https://safety4sea.com/port-of-antwerp-works-on-blockchain-pilot-project/ (accessed 23 September 2019).

Seebacher, S. and SchüRitz, R. (2017), "Blockchain technology as an enabler of service systems: a structured literature review", Lecture Notes in Business Information Processing Exploring Services Science, pp. 12-23.

Shome, A. (2017), "Estonia to launch its own cryptocurrency finance magnates - financial and business news", available at: www.financemagnates.com/cryptocurrency/news/estonia-launchcryptocurrency/ (accessed 18 March 2018).

Skuchain (2018), "Skuchain: empower My supply chain Skuchain", available atwww.skuchain.com/. (accessed 19 March 2018).

Skwarek, V. (2017), "Blockchains as security-enabler for industrial IoT-applications", Asia Pacific Journal of Innovation and Entrepreneurship, Vol. 11 No. 3, pp. 301-311, doi: 10.1108/APJIE-12-2017-035.

Smart Port (2018), "Roadmaps - smart port smart port", available at: http:/smart-port.nl/roadmaps/ (accessed 19 March 2018).

Swan, M. (2015), Blockchain: Blueprint for a New Economy, O’Reilly Media.

Tallysticks (2018), “Tallysticks: import/export solutions Tallysticks.Io", available at: https://tallysticks. io/ (accessed 19 March 2018).

T-Mining (2018), "Antwerp start-up $t$-mining develops blockchain solution for safe, efficient container release Portofantwerp.Com”, available at: www.portofantwerp.com/en/news/antwerp-start-tmining-develops-blockchain-solution-safe-efficient-container-release (accessed March 18 2018).

Tradelens (2019), “TradeLens documentation”, available at: https://docs.tradelens.com/ (accessed 23 September 2019).

Tsiulin, S., Hilmola, O. and Goryaev, N. (2017), "Barriers towards development of urban consolidation centres and their implementation: literature review", World Review of Intermodal Transportation Research, Vol. 6 No. 3, pp. 251-272.

van Baalen, P., Zuidwijk, R. and van Nunen, J. (2008), "Port inter-organizational information systems: capabilities to service global supply chains", Foundations and Trends in Technology, Information and Operations Management, Vol. 2 Nos 2/3, pp. 81-241.

Vidal Vieira, J.G. and Fransoo, J.C. (2015), "How logistics performance of freight operators is affected by urban freight distribution issues", Transport Policy, Vol. 44, pp. 37-47.

Wang, Y., Jeong Hugh, H. and Paul, B.-D. (2018), "Understanding blockchain technology for future supply chains: a systematic literature review and research agenda", Supply Chain Management: An International Journal, Vol. 24 No. 1, pp. 62-84, doi: 10.1108/SCM-03-2018-0148.

Wang, Y., Singgih, M., Wang, J. and Rit, M. (2019), "Making sense of blockchain technology: how will it transform supply chains?", International Journal of Production Economics, Vol. 211, pp. 221-236.

Wright, M. (1997), "Authenticating electronic cash transactions", Computer Frand and Security, Vol. 1997 No. 4, pp. 10-13.

Wüst, K. and Gervais, A. (2017), “Do you need a blockchain?”, IACR Cryptology ePrint Archive.

Yuan, Y. and Wang, F. (2016), "Towards blockchain-based intelligent transportation systems", 2016 IEEE 19th International Conference on Intelligent Transportation Systems (ITSC) Windsor Oceanico Hotel, Rio de Janeiro. 
Zalan, T. (2018), "Born global on blockchain”, Review of International Business and Strategy, Vol. 28 No. 1, pp. 19-34.

Zhang, N., Zhong, S. and Tian, L. (2017), "Using blockchain to protect personal privacy in the scenario of online taxi-hailing", International Journal of Computers Communications and Control, Vol. 12 No. 6, pp. 886-902.

\section{Further reading}

Accenture (2018), "Blockchain | what it is and why it matters", available at: www.accenture.com/us-en/ insights/blockchain-index (accessed 13 October 2018).

Cargox (2018), "CargoX | reshaping the future of global trade with the world's first blockchain bill of lading", available at: https://cargox.io/ (accessed 20 December 2018).

Carlan, V., Sys, C. and Vanelslander, T. (2016), "How port community systems can contribute to port competitiveness: developing a cost-benefit framework", Research in Transportation Business and Management, doi: 10.1016/j.rtbm.2016.03.009.

Chain of Things (2018), "CS3: chain of shipping", Chain Of Things, available at: www.chainofthings. com/cs3chainofshipping/ (accessed 18 March 2018).

Chang, Y., Iakovou, E. and Shi, W. (2019), "Blockchain in global supply chains and cross border trade: a critical synthesis of the state-of-the-art, challenges and opportunities", International Journal of Production Research, Vol. 58 No. 7, pp. 1-18.

Czachorowski, K., Solesvik, M. and Kondratenko, Y. (2019), "The application of blockchain technology in the maritime industry", Studies in Systems, Decision and Control, Vol. 171, pp. 561-577.

Dasaklis, T.K., Casino, F. and Patsakis, C. (2019), "Defining granularity levels for supply chain traceability based on IoT and blockchain", International Conference On Omni-Layer Intelligent Systems, (Coins), May 5-7, 2019, Crete, ACM, New York, NY, doi: 10.1145/3312614.3312652.

Demirbas, D., Flint, H. and Bennett, D. (2014), "Supply chain interfaces between a port utilizing organisation and port operator", Supply Chain Management: An International Journal, Vol. 19 No. 1, pp. 79-97, doi: 10.1108/SCM-04-2013-0137.

Dobler, M., Ballandies, M. and Holzwarth, V. (2019), "On the extension of digital ecosystems for SCM and customs with distributed ledger technologies: requirements anlysis, innovation assessment, and prototype design for the lake constance region", Proceedings - 2019 IEEE International Conference on Engineering, Technology and Innovation, ICE/ITMC 2019.

Engelenburg, S., Janssen, M. and Klievink, B. (2019), "Design of a software architecture supporting business-to-government information sharing to improve public safety and security: combining business rules, events and blockchain technology", Journal of Intelligent Information Systems, Vol. 52 No. 3, pp. 595-618.

Enterprise Times (2018), "AB InBev, Accenture, APL and Kuehne + Nagel successfully test blockchain”, available at: www.enterprisetimes.co.uk/2018/03/19/ab-inbev-accenture-apl-andkuehne-nagel-successfully-test-blockchain/ (accessed 13 October 2018).

Gao, Z., Xu, L., Turner, G., Patel, B., Diallo, N., Chen, L. and Shi, W. (2018), "Blockchain-based identity management with mobile device", CRYBLOCK 2018 - Proceedings of the 1st Workshop on Cryptocurrencies and Blockchains for Distributed Systems, Part of MobiSys 2018, p. 66.

Gausdal, A.H., Czachorowski, K.V. and Solesvik, M.Z. (2018), "Applying blockchain technology: evidence from Norwegian companies", Sustainability, Vol. 10 No. 6.

Gregorio, D. and Nustad, R.S. (2017), "Blockchain adoption in the shipping industry: a study of adoption likelihood and scenario-based opportunities and risks for IT service providers", Doctoral dissertation, Master Thesis in International Business, doi: 10.13140/ RG.2.2.21839.38561.

Hafizon, M.I., Wicaksono, A. and Farizan, F.N. (2019), "E-Toll LaUT: blockchain port as the key for realizing Indonesia's maritime fulcrum”, ACM International Conference Proceeding Series, p. 36.

Blockchainbased applications 
RIBS

30,2

Hyperledger (2018), “Composer supply chain network Github”, available at: https:/github.com/ aprilsnows/hyperledger-composer-supply-chain-network (accessed 18 March 2018).

Kamble, S.S., Gunasekaran, A. and Gawankar, S.A. (2020), "Achieving sustainable performance in a data-driven agriculture supply chain: a review for research and applications", International Journal of Production Economics, Vol.219, pp. 179-194.

Koteska, B., Karafilovski, E. and Mishev, A. (2017), "Blockchain implementation quality challenges: a literature review", Proceedings of the SQAMIA 2017: 6th Workshop of Software Quality, Analysis, Monitoring, Improvement, and Applications, Belgrade, pp. 11-13.

Kshetri, N. (2017), "Blockchain's roles in strengthening cybersecurity and protecting privacy", Telecommunications Policy, Vol. 41 No. 10, pp. 1027-1038.

LOGISTIK HEUTE (2018), "Logistik-IT: ROboBsoll hamburger hafensicherermachen”, available at: https://logistik-heute.de/news/logistik-it-robob-soll-hamburger-hafen-sicherer-machen-15022. html (accessed 20 December 2018).

Loklindt, C., Moeller, M.-P. and Kinra, A. (2018), "How blockchain could be implemented for exchanging documentation in the shipping industry", 6th International Conference LDIC 2018, Bremen, doi: 10.1007/978-3-319-74225-0_27.

Meherishi, L., Narayana, S.A. and Ranjani, K.S. (2019), "Sustainable packaging for supply chain management in the circular economy: a review", Journal of Cleaner Production, Vol. 237, p. 117582, ISSN 0959-6526.

Porttechnology (2018), "MSC and Abu Dhabi ports sign blockchain collaboration", available at: www. porttechnology.org/news/msc_and_abu_dhabi_ports_sign_blockchain_collaboration (accessed 14 December 2018).

Saberi, S., Kouhizadeh, M., Sarkis, J. and Shen, L. (2019), "Blockchain technology and its relationships to sustainable supply chain management", International Journal of Production Research, Vol. 57 No. 7, pp. 2117-2135, doi: 10.1080/00207543.2018.1533261.

Silverajan, B., Ocak, M. and Nagel, B. (2018), "Cybersecurity attacks and defences for unmanned smart ships", Proceedings - IEEE 2018 International Congress on Cybermatics: 2018 IEEE Conferences on Internet of Things, Green Computing and Communications, Cyber, Physical and Social Computing, Smart Data, Blockchain, Computer and Information Technology, p. 15.

SolasVGM (2018), "Product features SOLAS VGM", available at: http://solasvgm.com/product-features/ . (accessed 19 March 2018).

TEU Tokens (2018), "TEU tokens - Bitcoin for the shipping industry", available at: https://300cubits. tech/ (accessed 14 December 2018).

Tijan, E., Aksentijević, S., Ivanić, K. and Jardas, M. (2019), "Blockchain technology implementation in logistics", Sustainability, Vol. 11 No. 4.

Treiblmaier, H. (2018), "The impact of the blockchain on the supply chain: a theory-based research framework and a call for action”, Supply Chain Management: An International Journal, Vol. 23 No. 6, pp. 545-559.

Weernink, M.O. van den Engh, W. Francisconi, M. and Thorborg, F. (2017), "The blockchain potential for port logistics", Delft University of Technology, available at: http://smart-port.nl/wp-content/ uploads/2017/06/Bijlage-6_White-Paper-Blockchain.pdf (accessed 17 March 2018).

\section{Corresponding author}

Sergey Tsiulin can be contacted at: sergi.tsiulin@gmail.com

For instructions on how to order reprints of this article, please visit our website:

www.emeraldgrouppublishing.com/licensing/reprints.htm

Or contact us for further details: permissions@emeraldinsight.com 